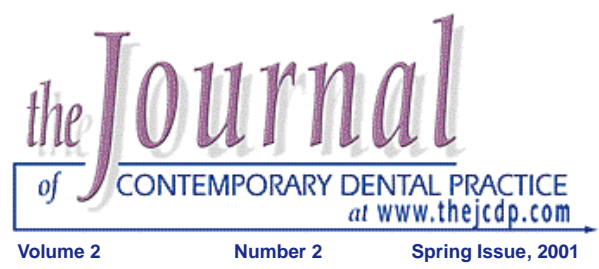

\title{
One Step at a Time: A Game Plan for Success
}

\section{Steven Schwartz, DDS}

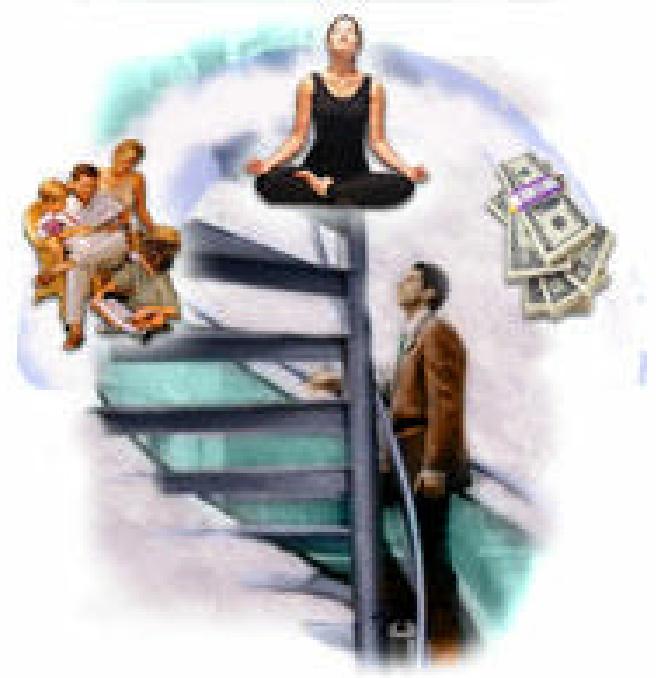

\section{Abstract}

Personal success is more likely to occur if individuals establish a concise action plan for achieving their goals. The action plan needs to be in writing, and it should include specific goals, success values, the tasks required to reach the goals, and the intended dates of completion of each task and goal. Goal setting can be accomplished through mental visualization of the goal. A method for creating an action plan is presented in this article.

Keywords: Personal goals, goal setting, visualization, success values 


\section{Introduction}

The Greek philosopher Aristotle wrote, "All men seek one goal: success or happiness. First have a definite clear, practical ideal - a goal, an objective. Second have the necessary means to achieve your ends - wisdom, money, materials, and methods. Third, adjust all your means to that end. Similarly, modern day philosopher and baseball great, Yogi Berra stated, "If you don't know where you're going, you'll probably end up somewhere else."

A study of 1953 Yale University graduates demonstrates this point. Graduates were asked if they had written goals with a plan for achieving goals. Only 3\% answered affirmatively. Twenty years later, researchers interviewed surviving members of the class again. They found the $3 \%$ with written goals were worth more financially than the other $97 \%$ put together . The researchers also found this group felt a greater degree of happiness and success than the group without specific goals.

\section{Goal Setting}

As important as goal setting is in achieving suc cess, most people spend more time shopping for a new car than planning their lives by setting goals. The problem most people have with achieving their goals is the goals they set for themselves are vague and general and, thus, seem too overwhelming to achieve. When setting goals, you must clarify your outcomes in detail and then determine exactly how to accomplish them. The most effective way to successfully ful fill your goals is to follow a written game plan that will provide a step-by-step process to setting and achieving goals. Once a clear game plan is insti tuted, you can break down major goals that seem too overwhelming to achieve into smaller more manageable minor goals and tasks. One must approach setting and achieving goals very much like one faces the task of eating an elephant... one step at atime.

Whether you are just starting a career or been in practice for 20 years, it is important you develop a goal setting routine that will clarify your goals and give you the direction in which to achieve them. By completing and following a "Game Plan for Success" (Figure 1), you will successfully achieve your long-term and short-term goals.

\section{Success Values}

The first step in your game plan is to identify and write down your "success values." Success val ues are principles and beliefs that are important to you. By identifying them you avoid setting goals that are inappropriate or in conflict with your life style. For example, suppose you have a suc cess value, "Everything I do will be in the best interest of my family." One of your goals as a parent may be to attend as many of your child's school events, sports activities, and religious functions as possible. This goal would be sup ported by your success value. However, you may also have a goal of establishing a high volume/high production practice with the necessity of devoting many hours over many days to work instead of being with your family. This goal would be in conflict with your success value, resulting in resentment and dissatisfaction with your practice.

If you have difficulty in defining your own success values, look to outside sources and adopt those values as your own. The bible and sermons, inspirational books, and books of quotations are sources for success values. Defining your suc cess values is the foundation on which your goals will rest.

Once you have defined your success values you are ready to establish and institute the goal set ting process by creating your game plan. The goal setting process entails visualizing long-term (major goals) and then breaking them down into more manageable short-term (minor goals) and tasks.

\section{Visualization}

The most effective way to begin the goal setting process is through visualiza-

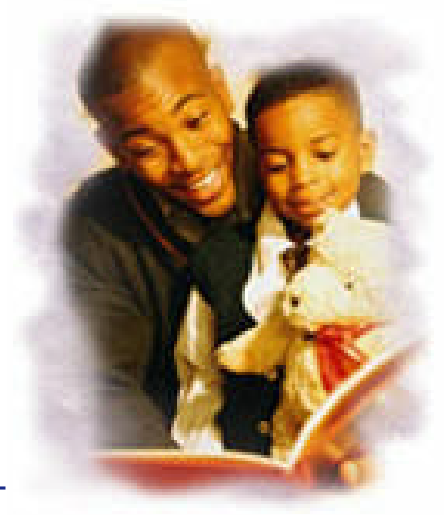
tion. CEOs of major corporations and star athletes attribute their success to visualization. Walt Disney died before he ever had a chance to step inside Disney World, 
Figure 1.

GAME PLAN FOR SUCCESS
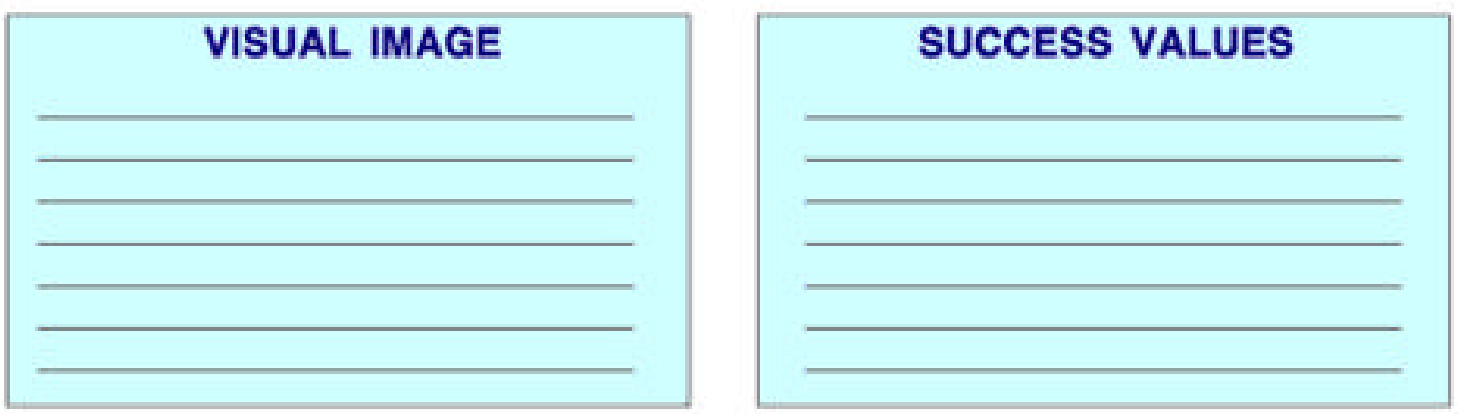

MAJOR GOAL

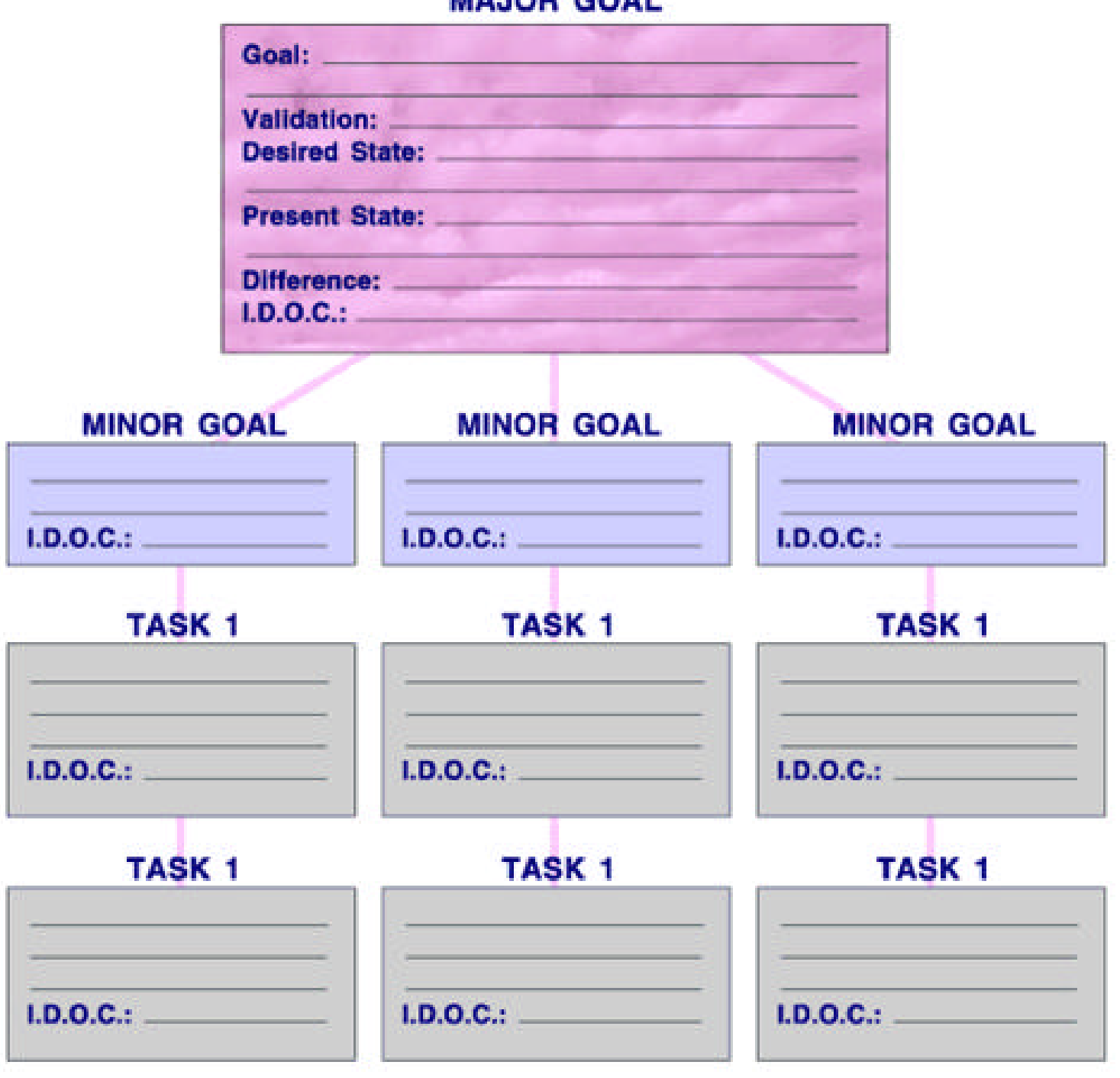


but by using visualization he knew exactly how the complex would look when completed. At age twelve, golf pro Tiger Woods visualized himself winning the Master's Tournament and embarked

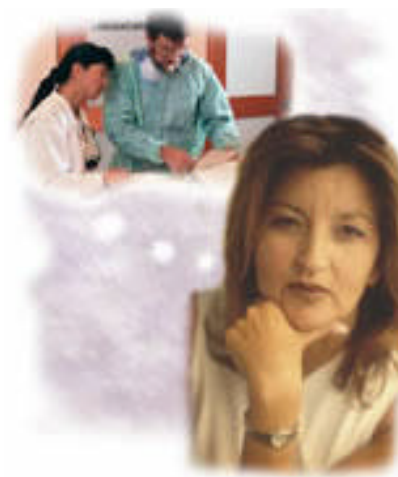
on the necessary training to achieve that goal.

There are six steps in the visualization process. Depending on your ambition and the grandeur of your goals the visualization process can take from fifteen minutes to 2 hours to complete per goal.

Begin the visualization process by finding a com fortable and quiet place to sit. (Don't lie down; you'll fall asleep). Have a blank Game Plan avail able. You can copy Figure 1 or adapt it for your own use. When comfortable, take a few deep breaths to relax yourself. Close your eyes and raise them toward your forehead. Imagine you are in a theater, standing in the middle of the stage. The goal setting process begins by visual izing yourself in your desired state or situation by answering the following questions.

\section{What exactly do you want?}

State your goal in positive terms. Avoid using words like "wish" or "want." Use "will" to state your goal. "I will lose 30 pounds in six months." "I will break a golf score of 80 by the end of the summer." "I will retire from my practice with an accumulated wealth of two million dollars at age 60."

What will I see, hear, feel, smell, and taste? If you don't know what you will feel when you reach your goal, you won't know when you've reached it. Each visualization of a goal should be as specific and vivid as your imagination will allow. When Tiger Woods visualized himself winning the Master's Tournament, he actually pictured himself sinking that last putt. In his mind he saw the ball rolling toward the cup. He heard the crowd roar as the ball fell into the cup. He felt his father hug him. He pictured himself receiving the trophy while wearing the green victory jacket.
Do the same for your goal. Record your specific feelings and visions. If your goal is to have a large practice, visualize yourself standing in the middle of your business office watching three financial coordinators collecting fees, inputting the information into the computers, and scheduling appointments. Watch and listen to the receptionists answering the phone. Picture the office decor and hear the music playing in the back ground. Experience the office in the environment in your mind.

As you visualize each goal, open your eyes and record the details of your goals in the "Visual Image" section of the Game Plan; devote a differ ent page to each goal. If you are unable to per form or are uncomfortable with the visualization process (maybe you were constantly hit in the head as a child by your teachers for daydream ing), you can import an image from an outside source. Suppose you have a goal of spending your retirement fishing. Find a picture of a fisher man on a boat in a lake and paste your face in the picture. Paste the composite picture in the Visual Image box on the Game Plan. The visual image will act as a constant reminder of your goal(s) and help you remain focused on their real ization. (Figure 2)

\section{Why are these goals important to me?}

You must validate your goals. Unless you can come up with a good reason for your goals, it will be difficult to stay focused to achieve them. For example, if your goal to be fit and maintain a specific weight is to enable you to live a long, healthy, active life, you will constantly work toward reaching and main taining that goal. If your reason for losing weight is to get into a special suit or dress to wear to your twenty-year high school reunion, you'll work hard to reach your goal initially. Once the reunion has passed and you have impressed your old sweetheart, your motivation to continue working toward that goal will be diminished. 
Figure 2.

GAME PLAN FOR SUCCESS

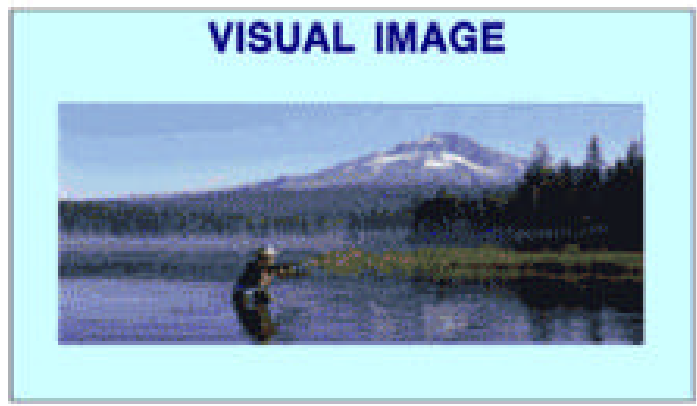

\section{SUCCESS VALUES}

- I will treat all people with fairness and respect.

- Everything I do will be in the best interest of my family.

- I will lead a life of moderation, planning for the future while enjoying the present.

\section{MAJOR GOAL}

Goal: I will retire with $\$ 2,000,000$ in accumulated wealth at age 60 in good physical and emotional health.

Validation: Provide time to enjoy family, hobbies Desired State: 60 years old, accumulated wealth of $\$ 2,000,000, \$ 0$ outstanding debt.

Present State: 26 years old, \$0 in savings, loans of $\$ 50,000$, DDS degree, associate in practice earning $\$ 50,000$.

Difference: 34 years, $-(\$ 2,050,000)$

I.D.O.C.: $06 / 30 / 31$

MINOR GOAL

I will have an accumulated wealth of $+\$ 100,000 \ldots$.

I.D.O.C.: 01/01/05

\section{TASK 1}

I will establish a profitable business ....

I.D.O.C.: 09/30/01

TASK 1

I will establish and follow a savings and investment plan I.D.O.C.: 01/30/02

\section{MINOR GOAL}

I will adopt a healthy lifestyle...

I.D.O.C.: 06/01/01

\section{TASK 1}

I will establish and follow a dally exercise plan ... I.D.O.C.: 06/01/01

\section{TASK 1}

I will follow a healthy diet and reduce calorie intake I.D.O.C.: 06/01/01

\section{MINOR GOAL}

I will learn how to be happy and enjoy life.... I.D.O.C.: 06/01/01

\section{TASK 1}

I will maintain a positive attitude ....

I.D.O.C.: 06/01/01

\section{TASK 1}

I will associate with people that make me comfortable I.D.O.C.: 06/01/01 
If your goal is to retire at a young age, validate the reason. Is it because you want to enjoy your family and hobbies while your still healthy? Is it because you hate your job? Is it just to impress others? The greater the validation, the greater the likelihood of fulfilling your goals. Record your validation on your Game Plan.

\section{How does my desired goal compare to my present state?}

This question can be divided into the following three questions:

-What do I want?

-What is happening now?

-What is the difference?

Achieving a goal is like planning a trip. If you know your starting point and you know your desti nation, you can calculate the distance you have to travel. By comparing your desired goal to your present state, you can begin to calculate the amount of effort, time, and resources required to reach the desired goal. You can also evaluate the resources and skills you currently possess that will help you achieve your goals. You may surprise yourself and find yourself closer to reaching some goals than you thought.

For example, if you are fifty years old and your goal is to retire at age sixty with the same lifestyle you currently enjoy, you have to determine how much money you will need in your retirement plan at the time of retirement and compare the amount to your current savings. If you lead a moderate lifestyle and have consistently saved over the years, you may find yourself closer to your goal than originally thought. If you maintained a high er lifestyle and contributed less to your retirement plan, you may find a greater disparity in what you need and what you have. To overcome this disparity you must make choices. You can continue with your current savings strategy and retire at a later age or you can reduce your lifestyle, contribute more to your retirement plan, and retire when planned. Before you can formulate strate gies to achieve your goals you have to know your starting point and your destination. Record your findings on your Game Plan.

What is my timetable for achieving my goal? Pinpoint a date by which you plan to achieve your major goal. Record this date in the space labeled
"Intended Date of Completion" (I.D.O.C.) in the Major Goal section in your Game Plan. Until you have a date by when you plan to reach your goal, you can't develop a timetable and strategies to succeed. Having the intended date of completion in front of you on a daily basis will help you remain focused on working toward achieving your goal.

Referring back to the previous example of retiring at a specific age. Your major goal is to retire in thirty years at age 60 with an accumulated wealth of two million dollars. You could spend every dollar you earn for 25 years and then attempt to accumulate two million dollars in the last 5 years of practice, but it is doubtful you would succeed. The realistic approach would be to set up a series of minor or short-term goals of 1 to 5 year dura tion over a 30-year period. If you used a pragmat ic strategy of saving $10 \%$ of your gross income each year, with compounded interest you would easily achieve your goal of saving two million dol lars over a 30-year period. Achieving short-term goals to reach long-term goals allows for more flexibility and motivation in reaching your major goal. If during one particular year depressed eco nomic conditions resulted in a deficit of income and savings, the deficit could be overcome by saving additional increments of income in succeeding years. Additionally, as a short-term goal is successfully realized, there is increased moti vation to fulfill the long-term goal. Successfully saving moderate amounts of income during the early years of practice creates increased motiva tion to continue with the program.

\section{What are my strategies to achieve my goal?}

Now is the time to create a step-by-step plan on how to achieve your goals. This is accomplished by breaking down your major goal into less overwhelming minor goals and supporting tasks.

Continuing with our example, our major goal of retiring from the practice at age 60 (30 years of practice) with an accumulat ed wealth of two million dollars can be broken down into two minor goals: 
Minor goal \#1: I will establish a highly profitable practice to produce a net income of $\$ 150,000$ by June 30, 2003.

Minor goal \#2: I will have an accumulated wealth of $\$ 100,000$ by January 1, 2005.

Take note that the minor goals, just as major goals, are written as positive statements. Under each minor goal are the tasks necessary to achieve the minor goal. The tasks necessary to achieve minor goal \#1, establishing a profitable practice, include:

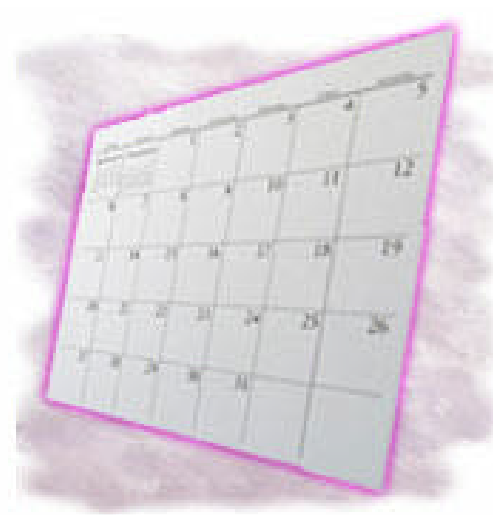

-Develop mechanisms for high production and collection of fees.

- Develop mechanisms for maintaining low overhead.

While the illustration (Figure 2) indicates only two tasks per minor goal, in reality it may be necessary to identify many more tasks to achieve your goal. Your Game Plan is not a static docu - ment. As you progress through life, your goals and ambitions become more complex resulting in a more complex game plan. As the number and complexity of the tasks increase, it may be neces sary to upgrade tasks to minor goals and minor goals to major goals. (Figure 3 ) In our example, if we upgrade the task "Develop processes for high production and collection of fees" to a minor goal, we can add a supporting task of "Participate in clinical and practice management courses."

Also note that each minor goal and task has its own intended date of completion. The I.D.O.C. for a task must be attained before the I.D.O.C. for a minor goal, and the I.D.O.C. for a minor goal must be attained before the I.D.O.C. for a major goal. It is said that life is a journey. If you're willing to let life take you anywhere it wants, every road you take will get you nowhere. Visualizing your goals and creating a game plan to achieve them will lead you to the shortest road to success. 


\section{Figure 3.}

\section{GAME PLAN FOR SUCCESS}

\section{VISUAL IMAGE}

- Practice located in suburban area of NY.

- 2400 sq. ft. in professional building.

- Four treatment rooms equipped with...

- Staff consisting of one receptionist, two assistants, one hygienist.

- Separate reception room for children and adults.

\section{SUCCESS VALUES}

- I will treat all people with fairness and respect.

- Everything I do will be in the best interest of my family.

- I will develop and provide optimum service and quality for my clients.

\section{MAJOR GOAL}

Goal: : I will establish a profitable business that will net me $\$ 100,000 /$ year while working 40 hours/week.

Validation: Provide the means to retire at age $60 \ldots$.

Desired State: Sales of $\$ 200,000 / y e a r$, overhead of $50 \%$.

Present State: DDS degree, associate in practice earning $\$ 50,000 /$ year, loans of $\$ 50,000$

Difference: 2 years, own practice earning $\$ 100,000$. loans of $\$ 125,000$

I.D.O.C.: $06 / 30 / 03$

MINOR GOAL

I will acquire funding of $\$ 100,000$ to finance practice.

I.D.O.C.: $06 / 30 / 01$

\section{TASK 1}

Develop and provide business plan to lending institutions.

I.D.O.C.: 03/30/01

\section{TASK 1}

Find location for practice that will fit my lifestyle.

I.D.O.C.: 03/30/01

\section{MINOR GOAL}

I will acquire the training to provide optimum service I.D.O.C.: 06/30/01

\section{TASK 1}

Attend continuing education courses.

I.D.O.C.: 06/30/01

\section{TASK 1}

Develop professional contacts for advice.

I.D.O.C.: 06/30/01 


\section{Additional Readings}

1. Dare to Win; Jack Canfield and Mark Victor Hanson, Berkely Publishing Group, 1996.

2. The Success Journey; John Maxwell, Thomas Nelson Publishers, 1997.

About the Author

\section{Steven Schwartz, DDS}

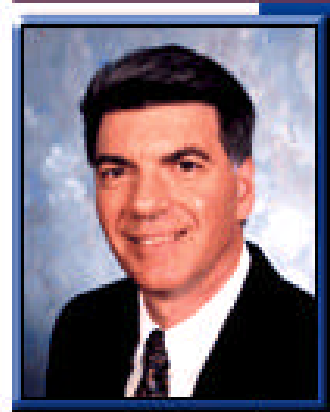

\section{Corresponding Author-}

Dr. Steven Schwartz has maintained a succtoslul pediatric dental practice since 1976. He is a diplomate of the American Board of Pediatric Dentistry and director of pediatric dentistry at Staten Island University Hospital. He is the author of numerous scientific and practice management articles, a member of the National Speakers Association and the primary lecturer for WOWI Seminars. Additional information can be found at WNWW.WOWSEMINARS.COM and he can be contacted by e-mail at: WOWSMNRSEAOL.COM 